\title{
SYNONIMIC FEATURES OF ADJECTIVES MEANING POSITIVE AND THEIR COLLOCATION FORMS
}

\author{
Barno Omonova Izzatullo qizi ${ }^{1}$ \\ ${ }^{1}$ A second-year student, \\ Faculty of Foreign philology, \\ Termez State University, UZBEKISTAN \\ Email: barnowa.amanova@mail.ru \\ ABSTRACT
}

Over the past two decades the concept of semantic prosody has attracted considerable research interest since Sinclair (1991) observed that "many uses of words and phrases show a tendency to occur in a certain semantic environment" (p. 112). Sinclair (2003) also noted that semantic prosody conveys its pragmatic meaning and attitudinal meaning. As the first scholar introducing the term 'semantic prosody,' Louw (1993) claimed that the habitual collocates of a lexical item are established through the semantic consistency of its subjects. Semantic prosody has thus been closely related to collocation learning in language acquisition research. In the context of collocation learning, near-synonyms particularly pose a difficulty for most foreign language learners due to their similar denotational meanings but un-interchangeable semantic prosody (Xiao \& McEnery, 2006). The present corpus-based study was designed to compare the semantic preference and semantic prosody with three synonymous adjective pairs picked up from the academic core words in COCA (Gardner \& Davies, 2013). The pairs were chosen based on the following criteria: a) their meanings were checked against Collins Thesaurus Online; b) the words with more than one meaning were removed; c) the word with more than one part of speech was defined the same as its paired word. All occurrences were examined manually at the span of 4 words to both the left and right. Discussion and implications were reported.

Keywords: Foreign language learners, semantic prosody, concordance lines, observations and insights, positive nouns.

\section{INTRODUCTION}

Having created numerous examples rich in observations and insights, Stubbs (2001) re-assessed the concept of semantic prosody and re-named it as 'discourse prosody' as a response to Sinclair's claims. Stubbs (2002) further acknowledged that "there are always semantic relations between node and collocates, and among the collocates themselves" (p. 225), and he grouped discourse prosody into three categories: positive, negative, and neutral.

By examining the concordance lines, the present study looked at the semantic preference and semantic prosody of three synonymous adjective pairs in the academic texts of COCA and also examined their semantic strength.

\section{LITERATURE REVIEW}

The importance of near-synonyms has received increasing attention in collocational classroombased research during the past decade or so (Hill, 2001; Lewis, 2001; Woolard, 2001, Webb \& Kagimoto, 2012). However, it is practically impossible to teach a large number of synonyms due to the limited teaching hours in the classrooms.

The questions are answered by registered users or language specialists in TELEC (Teachers of English Language Education Centre), housed in the Faculty of Education at The University of Hong Kong. One of the most frequently asked questions was whether there is any difference between words that are generally considered to be synonyms.

Some were cases in which teachers were not aware of any difference in meaning and usage, such as "big" and "large", "lastly" and "finally", others were cases in which they knew the difference in usage but could not fully articulate what the difference was, for example, "tall" and "high". Tsui concluded that Chinese learners often have difficulty in differentiating those near-synonyms because they have the same Chinese translations. Thus the Chinese explanations/translations did not help the students, even sometimes the learners' dictionaries offer only very concise explanations and limited examples with those synonymous pairs. 
However, take an example between high and tall, the concordance lines indicate that high was used in a metaphorical sense with more abstract nouns but tall appeared more frequently in contexts with concrete nouns such as people, tree, and building. To date, none of the studies focusing on semantic prosody has selected the target items from a specific academic list derived from corpus data.

Currently, researchers within academia across the world are under big pressure to read and publish large amounts of academic texts. One of the major media of the academic texts is undoubtedly English, whereas academic users are not definitely English native learners. One obstacle that may block the non-native learners on the road to academic success is the semantic preference and prosody with these synonymous word pairs while composing the academic texts.

The present study aimed to examine the semantic preference and semantic prosody with three synonymous adjective pairs picked up from the core word lists of AVL (the Academic Vocabulary List, Gardner \& Davies, 2013) across different academic disciplines, with an attempt to reinforce the professional development of foreign academic users by identifying the patterns of those synonymous pairs.

\section{THE PURPOSE AND OBJECTIVES OF THE WORK}

By comparing 570 words in both the AVL and AWL (Coxhead, 2000), Gardner and Davies observed that AVL demonstrates better coverage across different disciplines of the academic texts. The present study compared and contrasted 3 synonymous adjective pairs to observe their semantic preference and semantic prosody in academic texts of COCA. 2.2.

Only those pairs with mutual information of 3 were selected for comparison. Mutual information, which is involved in the COCA interface, was used in this study due to the following reasons.

First, it favours content words rather than function words as T-score does.

Second, an MI score of 3 or higher indicates that the two lexical items frequently co-occur.

Third, it complements the frequency measure in better identifying the adjectives that typically modify the nouns (Liu, 2010, 2013). The present study analyzed the following three adjective synonymous pairs: initial/preliminary, following/subsequent, and sufficient/adequate via the queries of frequency and mutual information score. The semantic patterns and general distributional patterns within each academic discipline were discerned after looking at the concordance lines of each pair.

\section{RESULT}

After observing the concordance lines of initial, it is found that its collocates mainly consist of two types: a specific point or period in progress/development (e.g., stages, treatment, stage, phase, step) and the act of doing something (e.g., evaluation, screening, training, reaction, coding). The vast majority of the collocates have strictly neutral prosody, as seen in the following sentences:

(1) The initial phase consisted of the analysis for the data generated from the pilot study.

(2) An initial step in a community action project is the gathering of a working leadership group.

(3) We made an initial investigation of data-driven line drawing in our earlier article.

(4) The member checks were transcribed verbatim and the initial coding procedures were followed.

(5) Increasing numbers of men are living five years beyond initial diagnosis and are considered long-term survivors. Shock, apparently a negative collocate, is found to be neutral or even positive in the contexts and serves as a transition from a low ebb to a better turnaround.

(6) Once the bad news has been delivered and the initial shock absorbed, let the client know exactly what you can do to help.

(7) After the initial shock, Edward found a new rhythm to his life.

(8) Once the participants overcame the initial shock and confusion, the feelings of doubt and insecurity were gradually dispelled. Interestingly, presentation, a neutral collocate, is largely associated with negative contexts in medical situations after looking at the concordance lines.

(9) A photograph at initial presentation shows post-aural swelling on the left side.

(10) At the initial presentation, CT through the temporal bone shows the tumour involvement of the right middle.

(11) Local recurrence can occur many years after the initial presentation, so lifelong follow-up is warranted. Preliminary A scrutiny of the collocates of preliminary reveals it co-occurs most frequently with neutral terms such as results, study, analysis, data, analyses, findings, investigation, evidence, followed by reporting verbs like suggest(s), indicate(s), the report used in neutral contexts.

(1) Our results offer preliminary evidence to support this hypothesis.

(2) Given the moderate sample size, these preliminary findings should be interpreted cautiously. 
(3) In effect, this article provides social workers with a preliminary assessment " toolbox.

(4) Thus, these studies generate preliminary evidence that indexical information may also inform recognition of artificially degraded speech. The verbs collocating with preliminary function as reporting and generalizing the results derived from some specific findings.

(5) At best, these preliminary exchanges suggest appropriate parameters for subsequent negotiations.

(6) Preliminary test data indicates that it will meet metal and other and application standards. Even the apparently negative collocate, injunction, turns out to be neutral legal jargon; all instances of a preliminary injunction are of the form:

(7) On Sept 4, a federal appeals court suspended a preliminary injunction that halted NIH in-house research.

(8) The three federal judges in Philadelphia granted the request for a preliminary injunction against the CDA. The investigation, which collocates with both initial and preliminary, appears to be a word that can be used interchangeably in educational, medical and legal contexts. However, there is a tendency that initial investigation appears more frequently in science texts, whereas preliminary investigation occurs mostly in social science texts. Out of the 60 occurrences of the initial investigation, 28 (46.6\%) of them appear in science texts, but there are only 11 occurrences of preliminary investigation out of $104(10.6 \%)$ in science texts.

(9) No measurements are taken during the initial investigation (Environmental Health).

(10) The best initial investigation in patients with thunderclap headache is emergency computed tomography (Medicine).

(11) As a present precursor, we began with a preliminary investigation of General Psychology textbooks (Educational Psychology).

Table 1. Frequency counts of the top 20 collocates for initial and preliminary across the nine academic fields in COCA.

\begin{tabular}{llllllllll}
\hline & HIS & EDU & SOC & LAW & HUM & PHIL & SCI & MED & BUS \\
\hline initial & 1136 & 1344 & 2167 & 835 & 922 & 934 & 2588 & 1749 & 421 \\
preliminary & 189 & 303 & 617 & 312 & 172 & 218 & 739 & 463 & 23 \\
\hline
\end{tabular}

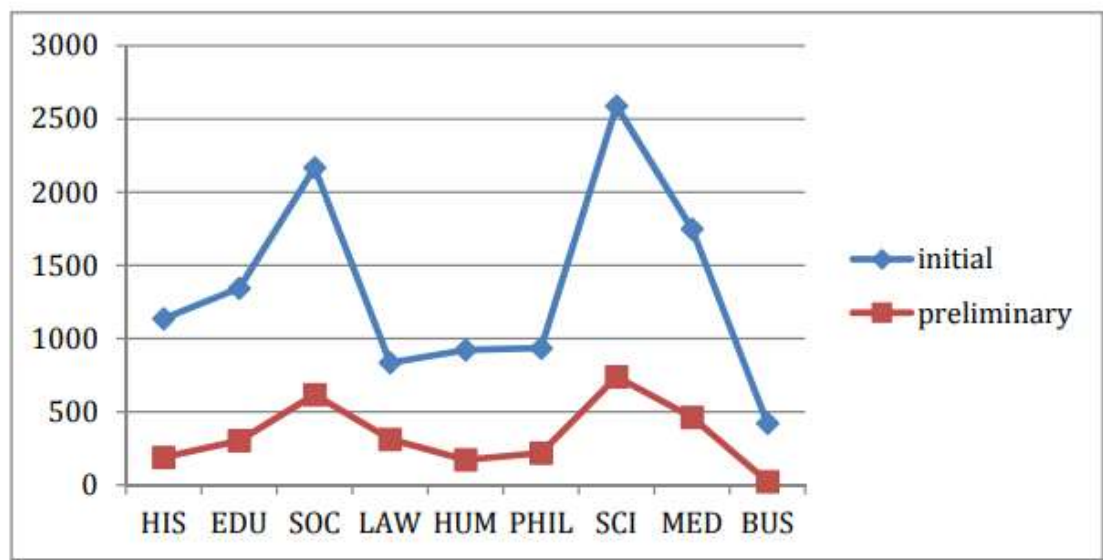

Figure 1. Frequency distribution of the top 20 collocates for initial and preliminary across the nine academic fields in COCA

Adjective, and adverb, and one other. That is, unlike the previous two adjective pairs whose frequent collocates are nouns mostly, verbs also co-occurs with sufficient very often. The noun collocates are those that can be measured in terms of quantity (e.g., resources, reason, condition, numbers, cause, detail, funds) in both neutral and negative contexts.

(1) In doing so, we found that there was sufficient evidence for only a few subsets of variables.

(2) A necessary and sufficient condition for asymptotic stabilizability of continuous-time uncertain switched linear systems.

(3) Mention places where there are not sufficient resources to meet curriculum and standards needs.

(4) Finally, though the natural light of reason is in principle sufficient for philosophical wisdom, sin has obscured that light. As mentioned above, sufficient is collocated frequently with more verbs than nouns. The Collins online dictionary defines sufficient as "assuring the truth of a statement; requiring but not 
necessarily required by some other state of affairs," as evidenced in the following concordance lines.

\section{CONCLUSION}

The result is predictable as academic registers tend to suppress, or at least to obscure, strong emotional connotation, for neutralizing the texts. Thus it seems that extremely polarized collocations will be relatively infrequent, regardless of a word's 'real world' connotations. Future studies could also examine in more specific details how each pair scatters across different academic disciplines. The synonyms could be compared in other registers (newspapers, magazines) to discover their different distributional patterns as well.

This study only looked at the evaluative/attitudinal meanings with the three adjective pairs, and researchers could also examine the functional and structural variations with the synonymous pairs. For instance, the colligation (i.e., the grammatical sentence structure) in association with the word's collocations can be inspected and analyzed altogether to identify the varying patterns between the pairs. Finally, some cross-linguistic comparisons could be done to examine the synonymous pairs along with their corresponding items to diagnose some clear-cut distinctions across different languages.

\section{REFERENCES}

[1] Gardner, D., \& Davies, M. (2013). A new academic vocabulary list. Applied Linguistics, 35(3), 305- 327. Doi:10.1093/applin/amt015. Hunston, S. (2002). Corpora in applied linguistics. Cambridge: Cambridge University Press.

[2] Liu D. (2010). Is it a chief, main, major, primary, or principal concern? A corpus-based behavioural profile study of the near-synonyms and its implications. International Journal of Corpus Linguistics, 15, 56-87. DOI: 10.1075/ijcl.15.1.

[3] Hunston, S. (2007). Semantic prosody revisited. International Journal of Corpus Linguistics, 12(2), 249-268. DOI: 10.1075/ijcl.12.2.

[4] Liu, D. (2013). Salience and construal in the use of synonymy: A study of two sets of near synonymous nouns. Cognitive Linguistics, 24, 67-113. DOI: 10.1515/cog-2013-0003

[5] Louw, W. E. (1993). "Irony in the Text or Insincerity in the Writer? In M. Baker (Ed.), The Diagnostic Potential of Semantic Prosodies." Text and Technology: In Honour of John Sinclair (pp. 157-176). Amsterdam: John Benjamins.

[6] Louw, B. (2000). Contextual prosodic theory: Bringing semantic prosodies to life. In Heffer, C., H. Saunton, and G. Fox (Eds.), Words in Context: A Tribute to John Sinclair on his Retirement (pp. 41-55). Birmingham: University of Birmingham.

[7] McEnery, T., \& Hardie, A. (2011). Corpus linguistics: method, theory, and practice. Cambridge: Cambridge University Press.

[8] Sinclair, J. (1991). Corpus, concordance, and collocation. Oxford: Oxford University Press.

[9] Sinclair, J. (1996). The empty lexicon. International journal of corpus linguistics, 1(1), 99-119.

[10] Sinclair, J. (2003). Reading concordances: An introduction. London: Pearson Longman.

[11] Stubbs, M. (2002). Two quantitative methods of studying phraseology in English. International Journal of Corpus Linguistics 7 (2), 215-244.

[12] Stewart, D. (2010). Semantic prosody: A critical evaluation. Routledge: Taylor \& Francis.

[13] Irgashevich, D. A. (2020). Development of national network (tas-ix). ACADEMICIA: An International Multidisciplinary Research Journal, 10(5), 144-151. Article http://dx.doi.org/10.5958/2249$\underline{7137.2020 .00254 .2}$ 